\title{
Prospective evaluation of quality of life effects in patients undergoing palliative radiotherapy for brain metastases
}

Diana Steinmann ${ }^{1 *}$, Yvonne Paelecke-Habermann $^{2}$, Hans Geinitz $^{3}$, Raimund Aschoff ${ }^{4}$, Anja Bayerl ${ }^{5}$, Tobias Bölling ${ }^{6}$, Elisabeth Bosch ${ }^{7}$, Frank Bruns ${ }^{1}$, Ute Eichenseder-Seiss ${ }^{5}$, Johanna Gerstein ${ }^{8}$, Nadine Gharbi ${ }^{3}$, Juliane Hagg ${ }^{9}$, Matthias Hipp ${ }^{10}$, Irmgard Kleff ${ }^{11}$, Axel Müller ${ }^{3}$, Christof Schäfer ${ }^{10}$, Ursula Schleicher ${ }^{7}$, Susanne Sehlen ${ }^{12}$, Marilena Theodorou ${ }^{3}$, Hans-Joachim Wypior ${ }^{13}$, Franz Zehentmayr ${ }^{14}$, Birgitt van Oorschot ${ }^{15}$ and Dirk Vordermark ${ }^{16 t}$

\begin{abstract}
Background: Recently published results of quality of life (QoL) studies indicated different outcomes of palliative radiotherapy for brain metastases. This prospective multi-center QoL study of patients with brain metastases was designed to investigate which QoL domains improve or worsen after palliative radiotherapy and which might provide prognostic information.
\end{abstract}

Methods: From 01/2007-01/2009, n=151 patients with previously untreated brain metastases were recruited at 14 centers in Germany and Austria. Most patients (82\%) received whole-brain radiotherapy. QoL was measured with the EORTC-QLQ-C15-PAL and brain module BN20 before the start of radiotherapy and after 3 months.

Results: At 3 months, 88/142 (62 \%) survived. Nine patients were not able to be followed up. 62 patients (70.5 \% of 3 -month survivors) completed the second set of questionnaires. Three months after the start of radiotherapy QoL deteriorated significantly in the areas of global QoL, physical function, fatigue, nausea, pain, appetite loss, hair loss, drowsiness, motor dysfunction, communication deficit and weakness of legs. Although the use of corticosteroid at 3 months could be reduced compared to pre-treatment ( $63 \%$ vs. $37 \%$ ), the score for headaches remained stable. Initial QoL at the start of treatment was better in those alive than in those deceased at 3 months, significantly for physical function, motor dysfunction and the symptom scales fatigue, pain, appetite loss and weakness of legs. In a multivariate model, lower Karnofsky performance score, higher age and higher pain ratings before radiotherapy were prognostic of 3-month survival.

Conclusions: Moderate deterioration in several QoL domains was predominantly observed three months after start of palliative radiotherapy for brain metastases. Future studies will need to address the individual subjective benefit or burden from such treatment. Baseline QoL scores before palliative radiotherapy for brain metastases may contain prognostic information.

Keywords: Brain tumours, EORTC-QLQ-C15-PAL, EORTC-BN20, Whole-brain radiotherapy

\footnotetext{
* Correspondence: Steinmann.Diana@mh-hannover.de

${ }^{\dagger}$ Equal contributors

${ }^{1}$ Radiation Oncology, Medical School Hannover, Hannover, Germany

Full list of author information is available at the end of the article
} 


\section{Background}

Quality of life (QoL) is now considered an important endpoint in oncological studies and is essential for the assessment of different therapeutic options. Knowledge about health-related QoL could help physicians, patients and even family members to achieve a better understanding of the treatment outcomes of cancer patients and make appropriate decisions. In the literature controversial results of measurement of QoL in patients with brain metastases have been reported [1-5]. Differences may have been caused by diverse points of time of assessment and the variety of fractionation schemes and patient cohorts. These results led us to address prospectively the question of the development of QoL over time within three months after initiation of palliative radiotherapy for brain metastases.

Physicians often estimate survival of patients much more positively than is realistic, potentially resulting in aggressive therapies without benefit [6,7]. The most commonly used instrument to estimate survival objectively in patients with brain metastases is the recursive partitioning analysis (RPA) [8,9] which relates overall survival after whole-brain radiotherapy (WBRT) to Karnofsky performance status (KPS), extracranial tumour status and age $[10,11]$. The more recently proposed graded prognostic assessment (GPA) included the number of brain metastases [12]. Rades et al. published a new scoring system to predict the survival of these patients treated with WBRT [11] and added the interval from tumour diagnosis to WBRT (longer time is better) to the criteria of RPA. They suggested an approach in which more favourable patients could be treated with longer-course WBRT to reduce neurotoxicity and other patients with poor prognosis could benefit from shortcourse WBRT.

Results of our prospective quality-of-life pilot study [1] indicated, that the initial QoL at start of radiotherapy was better in patients found to be alive at 3 months than in those deceased within 3 months. We therefore hypothesized that QoL at initiation of radiotherapy, may be an independent prognostic factor for survival of patients with brain metastases. Additionally, we observed a worsening of QoL in most domains in the pilot study, significant in drowsiness, hair loss and weakness of legs, during the first three months after the start of palliative radiotherapy for brain metastases. Other studies showed similar results with statistically significant deteriorations in fatigue [3], drowsiness and appetite [5] after the delivery of palliative radiotherapy for brain metastases.

Because our pilot study was limited by the small number of only $n=17$ patients providing QoL data at the 3month time point, we performed a follow-up large-scale study to address the following questions:
Which pre-treatment QoL domains and symptom scales increased or decreased significantly after 3 months? Which clinical characteristics influence the QoL after 3 months? What could be a benefit of radiotherapy?

Which pre-treatment QoL scales of the 3-monthsurvivors are significantly different from those of the non-survivors and could be a prognostic factor?

\section{Methods}

\section{Recruitment}

Patients with previously untreated brain metastases of solid tumours were recruited at 14 radiation oncology centres. Exclusion criteria were language barriers, insufficient compliance or cognitive status and chemotherapy during planned radiotherapy. After informed consent questionnaires EORTC QLQ-C15-PAL and BN20 were handed out to patients at the time of the initial consultation for the planned palliative brain radiotherapy. Patient and treatment characteristics, KPS and Barthel Index [13], a scale summarizing the ability to perform activities of daily living, were collected using patient records and documented follow up. Three months after the first radiotherapy session, survival status of patients was determined. We called patients by telephone and asked about their situation and performance. After that (if it was ethical), we sent out questionnaires with a stamped self-addressed envelope. If patients came for follow-up visits at the clinic, we also used this as an opportunity to hand out the questionnaire.

Ethics approval was obtained from the ethics committee at the University of Würzburg, Germany.

\section{Quality-of-life questionnaires}

QLQ-C15-PAL and BN20 validated instruments were developed by the European Organization for Research and Treatment of Cancer (EORTC) Quality of Life Study Group for measuring the QoL of cancer patients in clinical trials [14]. QLQ-C15-PAL is a shortened form of QLQ-C30 for use in a palliative care setting, containing 15 items for the following nine domains: physical function, emotional function, global QoL, pain, fatigue, appetite, dyspnea, constipation and sleep. Each item is scored from 1 to 4 ("not at all": 1; "a little": 2; "quite a bit": 3 ; "very much":4). As an exception, global QoL is scored from 1 ("very poor") to 7 ("excellent"). The results for these domains are directly comparable between QLQC30 and QLQ-C15-PAL [15].

The BN20 questionnaire is a brain-specific module to be used in conjunction with the generic EORTC questionnaires and contains 20 items grouped into four domains (future uncertainty - four items, visual disorder, motor dysfunction and communication deficit each three items) as well as seven single items 
(headaches, seizures, drowsiness, hair loss, itchy skin, weakness of legs, bladder control).

Questionnaire data were processed according to the procedures outlined in the EORTC QLQ-C30 scoring manual and the addendum for scoring of QLQ-C15-PAL $[15,16]$. For functional scales and global QoL, high scores represent good functioning/ good QoL. For the symptom scales and for all scales of BN20, high scores indicate severe symptoms.

We asked proxies of patients to simultaneously participate in a separate questionnaire to report the QoL of their relative. Results of the proxy assessment in the main study will be published separately.

\section{Statistical analysis}

The ratings of each item of both questionnaires were linearly transformed to a 0-100 scale, with 'not at all' conforming to 0 and 'very much' conforming to 100 [15]. QoL scores were then analyzed parametrically [17]. Mean change in scores about 10 to 20 ("moderate") and greater than 20 ("worse") were considered clinically relevant [18].

Means, mean differences, SEs, test statistics and pvalues for all QoL subscales, separate for time points and patient groups, were calculated.

Paired t-tests were used to compare the patients' mean scores between the points in time. For each scale, a multiple regression analysis was used to find the best prediction equation for the change of QoL ratings after three months. The following variables were included in the analysis: pre-therapeutic KPS, age, number of cerebral metastases [1-3 vs. >3], therapeutic strategy [WBRT vs. SRS/hfSRT], localization [breast, lung, other], and pre-therapeutic status of the primary tumour [progressive vs. non-progressive]. Dummy variables were created for all nominal variables with more than two categories. Variables without significant influence were excluded backwards. This method avoids insignificant predictors and can exclude intercorrelated predictors.

Student's t-tests for independent samples were used to test differences in the QLQ scales between 3-monthsurvivors and non-survivors. A multiple logistic regression model was used to test which variables can significantly predict 3-month survival. The QoL scales with significant change in the pilot study (physical function, fatigue, pain, motor dysfunction, weakness of legs, communication deficit and headaches), and the mentioned non-QoL independent variables (number of brain metastases, extracranial primary tumour situation or extracranial metastases, KPS, age, primary tumour) were included in the analysis. Variables without significant influence were excluded stepwise backwards.

The significance level was set to .05. For further explorative analyzes, the significance level was set to .01 to adjust for multiple comparisons (several scales and groups).

\section{Results}

Patients and treatment characteristics

Including patients of the pilot study $(n=64)$ [1] 151 patients with previously untreated brain metastases were recruited at 14 centres in Germany and Austria from 01/ 07 to $01 / 09$. Most patients were recruited in only few (6) centres with 10 to 50 patients. Other centres were only small and recruited only few patients with brain metastases. The dominant radiotherapy strategy $(\mathrm{n}=131$, $88.5 \%)$ was whole-brain radiotherapy (WBRT) alone. Eight patients additionally received boost irradiation, 17 (11.5\%) patients stereotactic radiosurgery (SRS), hypofractionated stereotactic radiotherapy (hfSRT) or 3Dconformal local radiotherapy alone.

Patient and treatment characteristics, including the pre-treatment KPS and the Barthel index are presented in Table 1. The survival status was known in 142 patients, 54 (38\%) had died within three months (until 90 days) after beginning of radiation therapy. Median overall survival was 135 days (4.5 months), 5.6 months for patients with limited (1-3) brain metastases and 3.4 months of patients with multiple brain metastases.

\section{Completion of questionnaires}

All 151 patients completed baseline QoL questionnaires EORTC QLQ-C15-PAL; 149 patients the BN20. 66 patients completed questionnaires at both time points. 53 of them were returned after 3 months (range 60120 days from initiation of radiotherapy). One patient filled in the second questionnaire 70 days after start of radiotherapy and died on day 87 . The response rate of 3-month survivors (>90 days) was 62 of 88 (70.5\%).

\section{QoL after 3 months in comparison to pre-treatment}

Self-assessed QoL was compared for the time points before and three months after the start of radiotherapy, including only data from patients who completed questionnaires both at the start of radiotherapy and after 3 months, to eliminate a potential bias resulting from a selection of survivors at the latter point of time.

Explorative analysis regarding the QLQ-C15-PAL scales revealed a significant deterioration in global QoL $(\mathrm{p}=0.011)$, physical function $(\mathrm{p}<0.001)$, fatigue $(\mathrm{p}$ $<0.001)$, pain $(\mathrm{p}=0.034)$, nausea $(\mathrm{p}<0.001)$, and appetite loss $(\mathrm{p}<0.001)$. In the organ-specific BN20 module, a significant deterioration in drowsiness $(p<0.001)$, motor dysfunction $(\mathrm{p}=0.014)$, communication deficit $(\mathrm{p}=0.025)$ and weakness of legs $(\mathrm{p}<0.001)$ was noted, whereas a trend was observed for increased hair loss $(\mathrm{p}=0.068)$ and the score for headache remained unchanged (Figures 1a-b). 
Table 1 Baseline clinical and treatment characteristics of patients registered for prospective QoL assessment

\begin{tabular}{|c|c|c|c|}
\hline \multirow[t]{2}{*}{ age [years] } & \multirow{2}{*}{$\begin{array}{l}\text { median (range) } \\
\text { total }\end{array}$} & \multicolumn{2}{|c|}{$61(33-84)$} \\
\hline & & $n=151$ & $100 \%$ \\
\hline \multirow[t]{8}{*}{ primary tumor } & non-small cell lung cancer & 70 & 46 \\
\hline & small-cell lung cancer & 20 & 13 \\
\hline & melanoma & 12 & 8 \\
\hline & renal cell carcinoma & 7 & 5 \\
\hline & colorectal cancer & 3 & 2 \\
\hline & breast cancer & 25 & 17 \\
\hline & others & 12 & 8 \\
\hline & unknown & 2 & 1 \\
\hline \multirow[t]{3}{*}{ Karnofsky performance score } & $\geq 70$ & 119 & 79 \\
\hline & $<70$ & 30 & 20 \\
\hline & unknown & 2 & 1 \\
\hline \multirow[t]{4}{*}{ RPA classification } & 1 & 17 & 11 \\
\hline & 2 & 99 & 66 \\
\hline & 3 & 33 & 22 \\
\hline & unknown & 2 & 1 \\
\hline \multirow[t]{5}{*}{ GPA classification } & $0-1.0$ & 63 & 43 \\
\hline & $1.5-2.5$ & 70 & 48 \\
\hline & 3.0 & 11 & 7 \\
\hline & $3.5-4.0$ & 3 & 2 \\
\hline & unknown & 4 & 3 \\
\hline \multirow[t]{3}{*}{ Barthel index } & $90-100$ & 115 & 76 \\
\hline & $<90$ & 34 & 23 \\
\hline & unknown & 2 & 1 \\
\hline \multirow[t]{4}{*}{ fractionation of whole-brain radiotherapy } & $10 \times 3$ Gy & 80 & 53 \\
\hline & $14 \times 2.5$ Gy & 12 & 8 \\
\hline & others & 32 & 21 \\
\hline & unknown & 5 & 3 \\
\hline \multirow[t]{4}{*}{ fractionation of stereotactic radiotherapy } & $1 \times 18-20$ Gy & 10 & 7 \\
\hline & $7 \times 5 \mathrm{~Gy}$ & 4 & 3 \\
\hline & $5 \times 6 \mathrm{~Gy}$ & 4 & 3 \\
\hline & 10x4 Gy & 1 & 1 \\
\hline \multirow[t]{5}{*}{ initial steroid dose(prednisone equivalent) } & no steroids & 41 & 27 \\
\hline & daily dose $<50 \mathrm{mg}$ & 38 & 25 \\
\hline & daily dose $50-100 \mathrm{mg}$ & 38 & 25 \\
\hline & daily dose $>100 \mathrm{mg}$ & 26 & 17 \\
\hline & unknown & 8 & 5 \\
\hline \multirow[t]{5}{*}{ extracranial tumor status } & primary tumor (PT) not detectable & 54 & 36 \\
\hline & PT detectable, not progressive & 44 & 29 \\
\hline & PT progressive & 48 & 32 \\
\hline & PT status unknown & 5 & 3 \\
\hline & any extracranial metastases & 104 & 70 \\
\hline \multirow[t]{2}{*}{ intracranial tumor status } & $>3$ metastases & 83 & 56 \\
\hline & 1-3 metastases & 65 & 44 \\
\hline
\end{tabular}


Table 1 Baseline clinical and treatment characteristics of patients registered for prospective QoL assessment (Continued)

$\begin{array}{lll}\text { number of metastases unknown } & 4 & 3 \\ \text { largest metastasis }>2 \mathrm{~cm} & 53 & 35 \\ \text { diameter of metastases unknown } & 17 & 12\end{array}$

Steroid use of 3 months-survivors was significantly lower at the second point of time (63\% vs. $37 \%$, $\mathrm{p}=0.002$ ).

The therapeutic strategy (WBRT only: worse function, $\mathrm{p}=0.041$ ), and the localization of the primary tumour (breast: better function, $\mathrm{p}=0.025$ ) were significantly associated with the physical function score after three months. The therapeutic strategy (WBRT worse than SRS/hfSRT) was significantly associated with the fatigue score after three months $(\mathrm{p}=0.001)$.

The initial KPS score was significantly associated with the motor dysfunction ( $\mathrm{p}=0.004)$.

In several QoL domains, the baseline scores before treatment were significant predictors for the scores of the same domains after three months (global QoL p

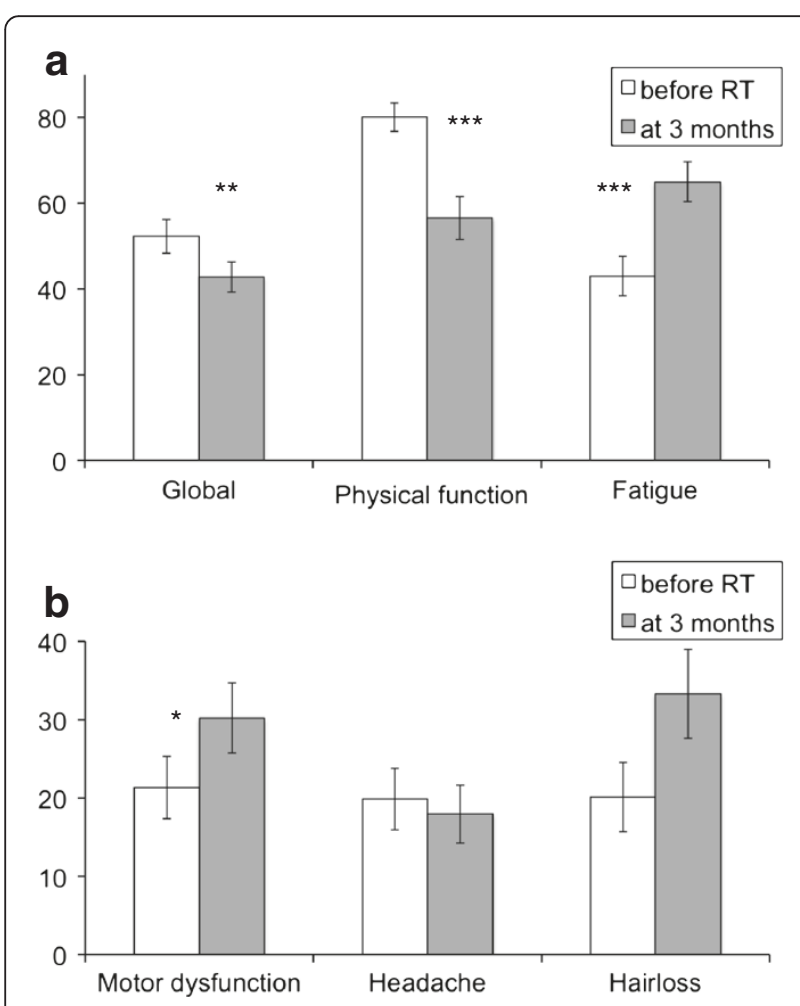

Figure 1 Self-assessed QoL in preselected QLQ scales before and 3 months after start of RT. a) EORTC QLQ C15-PAL: global QoL, physical function (higher score better), and fatigue (higher score worse). b) EORTC BN20: motor dysfunction, headaches and hairloss (all higher score worse) ${ }^{*} p<.05,{ }^{* *} p<.01$, ${ }^{* *} p<.001$; paired-t-test, one-tailed).
$<0.001$, physical function $\mathrm{p}=0.006$, fatigue $\mathrm{p}<0.001$, motor dysfunction $\mathrm{p}=0.001$, headache $\mathrm{p}=0.036$ ).

\section{Baseline QoL as prognostic factor for survival}

Baseline pre-treatment scores of physical function $(\mathrm{p}=0.001)$, fatigue $(\mathrm{p}=0.035)$, pain $(\mathrm{p}=0.01)$, motor dysfunction $(p=0.014)$, and weakness of legs $(p=0.006)$ were significantly better in 3-month survivors than in non-survivors (Figure 2a-b). However, no significant differences were detected in the remaining preselected domains of communication deficit and headache. Explorative analysis regarding the other QLQ-C15 PAL/ BN20 scales revealed a significant difference at baseline between 3-month survivors and non-survivors in the symptom scale of appetite loss $(\mathrm{p}<0.01)$.

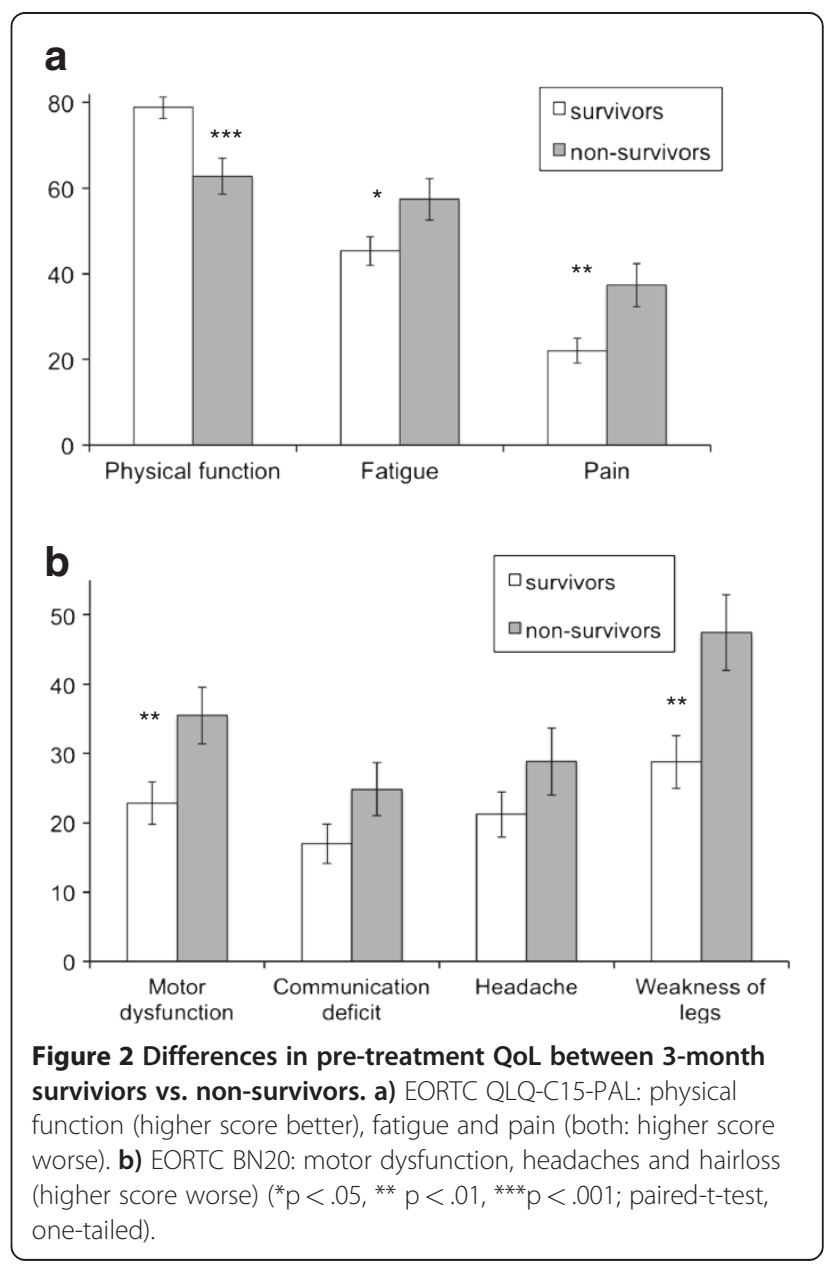


Using a multiple logistic stepwise regression model we found three significant predictors of 3-month survival. Patients with higher age $(\mathrm{p}=0.04)$, lower KPS scores $(\mathrm{p}=0.001)$, and higher pain scores (QLQ-C15-PAL score, $\mathrm{p}=0.04$ ) were found more frequently in the group of non-survivors.

\section{Discussion}

This prospective study generated a large QoL data set related to the radiotherapy of brain metastases with a validated brain-specific QoL questionnaire. Only one study group reported on a bigger patient group of 170 , but used a general QoL tool (ESAS - Edmonton Symptom Assessment Scale) without a brain-specific module [5].

Three smaller trials used the Functional Assessment of Cancer therapy - General scale (FACT-G) with a brain module (FACT-BR) [19-21]. The results are not comparable to our study because of the addition of temozolomide to WBRT [19] or different evaluation points of time. The brain module BN20 has been validated by the EORTC in an international study incorporating 891 patients with primary brain tumours [22] and has been applied in some smaller QoL studies of patients with brain metastases $[4,23,24]$. Because of short assessment periods $[4,15]$ after radiotherapy or analysis only of special radiation techniques like radiosurgery these studies are not directly acceptable to the routine palliative radiotherapy setting with predominant whole-brain radiotherapy and short survival times.

The BN20 questionnaire was used in this study with the shortened questionnaire variant EORTC QLQ-C15PAL to reduce the burden of repeated questionnaire completion for the incurable patients. It should be noted that the short version QLQ-C15-PAL lacks the two questions regarding cognitive function from QLQ-C30 [15], and therefore some potentially interesting information was lost by the decision for the shorter version.

QoL was evaluated at only two points in time. The second point of time after 3 months was chosen to reduce the effects of rapid deterioration by very early tumour progression, while maintaining a reasonable number of patients available for assessment. It must be acknowledged that the addition of both earlier and later points of time would have been informative. However, a distinction between brain-metastasis-related, extracranialtumour-related and treatment-related impairment would probably have been similarly problematic at other points of time. The choice of the 3-month-point was a compromise for pragmatic reasons. Given all the problems associated with the highly palliative situation of the patients studied, a response rate of $70 \%$ of survivors at this point of time appears adequate.
The overall survival in the patient group (38\% dead at three months) is comparable to other reports [3]. Previously, improved survival in patients with brain metastases has been linked to lower RPA class [10], higher GPA scores $[25,26]$, with stable extracranial tumour situation, limited (1-3) intracranial metastases and therefore possible radiosurgery $[27,28]$ and low steroid dose [29].

One of the most important results of this study was the deterioration of different domains and symptom scales of QoL in patients after three months. This was acceptable in potentially treatment-related symptom scales such as hair loss (only a trend in this study) and fatigue. In our study $42 \%$ and $54.2 \%$ of patients showed an increase of hair loss and fatigue scores, respectively, over 20 points. This can be considered clinically relevant. The study of Slotman et al. [17] examined QoL of patients with or without prophylactic cranial irradiation (PCI) for small-cell lung cancer with the same questionnaires. Slotman et al. [17] found a worsening hair loss ( $\geq$ 20 points) in $22.4 \%$ of patients with PCI and $12.2 \%$ of controls and a worsening of fatigue on this order of magnitude in $49 \%$ of patients with PCI and $26.7 \%$ of controls. Hair loss and fatigue are both also potential chemotherapy-associated symptoms. In our study subsequent chemotherapies after irradiation were not evaluated. Our findings are comparable with the results of Wong et al. who reported more severe fatigue symptoms in $57 \%$ of patients over time [3]. The testing of influencing factors in our study showed a significant association of WBRT as treatment strategy and the fatigue score after three months.

The score for headache was slightly better after 3 months in the pilot phase of this study and remained unchanged in the now reported main phase with a larger cohort of patients. Additionally, the steroid use after 3 months was significantly lower. Therefore, these results show one important benefit of the radiotherapy.

The deterioration of global health status, physical function and of symptom scales like motor dysfunction, communication deficit or weakness of legs after three months were not necessarily expected. The most important aim of brain irradiation in patients with brain metastases should be the improvement or stabilization of the performance status and of QoL.

Intracranial and extracranial progression or adverse treatment effects are potential explanations for the deterioration of QoL within three months after start of radiotherapy. Further published QoL studies did not analyze intra- or extracranial progression over time. This study provided some limited information on progression of the primary, additional extracranial and intracranial metastases or increase in the size of brain metastases. Due to the poor condition of most patients, it was felt to be unethical to require specific imaging studies to be 
performed at defined points of time. Imaging data after radiotherapy was available for $53 \%$ of patients and showed intracranial progression in $20 \%$ and extracranial progression in $53 \%$ of patients among these patients. For specific preselected QoL domains, predominant factors influencing the scores at the 3-month-point were identified. For instance, brain metastases from breast cancer were associated with better physical function at 3 months. This may be related to the known slightly better prognosis after radiotherapy for patients with brain metastases from breast cancer compared to other primaries [30] but also to the more recently documented improved outcome of subgroups e. g. with positive Her2 status [31].

A known prognostic factor in brain metastases patients, KPS, was associated with motor dysfunction after three months. The therapeutic strategy (WBRT vs. stereotactic radiotherapy) was significantly associated with the physical function score during the same period. Although the limited information on imaging response of brain metastasis precludes definitive conclusions, factors related to the initial selection of patients for specific strategies (e. g. stereotactic radiotherapy for fitter patients with limited number of metastases) are likely to explain part of the variation in post-radiotherapy QoL. Data from the literature suggests that achieving local control of brain metastases is a prerequisite for maintaining neurologic function[32]. Therefore, patients treated with palliative whole-brain radiotherapy alone may deteriorate not because of, but despite of radiotherapy, not considering the frequent rapid extracranial progression of metastases.

A second main result of this study was the difference of baseline QoL of 3-month survivors vs. non-survivors. Baseline pre-treatment QoL scores of physical function, fatigue, pain, appetite loss, motor dysfunction, weakness of legs were significantly better in survivors suggesting that these scores might contain prognostic information.

Similar results were presented by Movsas et al. who analyzed the QoL of 239 patients with locoregionally advanced non-small-cell lung cancer treated with amifostine and chemotherapy using the EORTC QLQ-C30 and LC-13 (RTOG 9801) [33]. Patients with a global QoL score less than 66.7 had an approximately $70 \%$ higher rate of death than patients with scores of $\geq 66.7$ $(\mathrm{p}=0.012)$. Other QoL predictors for OS were physical functioning and dyspnoea. In their study, these QoL scales seemed to be more relevant and powerful as prognostic factors than standard measures like KPS, so the authors suggested patient-reported QoL as a good stratification factor in future.

Other prior studies with lung cancer patients, who were also a predominant subgroup in the present cohort, have shown similiar results. Montezari et al. reported the initial global QoL as the most significant predictor of survival at 3 months [34]. In the literature, global QoL, appetite loss, fatigue and pain were the most important indicators for predicting survival times in cancer patients after adjusting known clinical prognostic factors $[35,36]$. It is argued that measures such as global QoL are patient-rated and thus have the potential to reflect the patient's well-being better than physician's observed indicators. Patient-reported outcomes detect prognostically relevant lowered patient well-being earlier than other measures. Higher scores correlate with more positive behaviour and reflect individual characteristics that affect survival [36]. Data for high-grade glioma patients defined fatigue as a prognostic factor [37] but no other trial has so far shown a specific QoL score of patients with brain metastases as predictive.

In the present study, using a multiple logistic stepwise regression model, only pain as one of six predetermined QoL domains, when tested together with clinical variables, remained prognostically significant. KPS and age were also significant predictors of survival. One possible explanation is that the KPS, as a global performance measure, contains information overlapping with that of the selected QoL domains. It could be argued that KPS alone integrates some of the prognostically relevant information obtainable from the QoL questionnaires. The prognostic role of pain, as assessed by EORTC QLQC15-PAL, for survival may be that on an indicator of uncontrolled extracranial disease. Sundaresan et al. developed a prognostic index for patients with WBRT for brain metastases of lung cancer and scored the factors age, ECOG performance status, histology, weight loss, primary and systemic disease status [38]. The new scoring system suggested by Rades et al. predicted the survival of all patients with brain metastases treated with WBRT [11]. Actuarial 6-month survival varied from $6 \%$ of patients in the worst prognostic group, via $15 \%$ and $43 \%$ to $76 \%$ of patients with better status. No QoL scores were used because of the retrospective nature of these studies. Sperduto et al. defined a disease-specific GPA, because patients with brain metastases are a heterogeneous population and different primaries are not comparable [26].

Potentially, the inclusion of self-reported QoL scores in prognostic scoring systems for patients with brain metastases may be more relevant within more specifically defined patients subgroups, e. g. only lung cancer or breast cancer patients. Given the generally unsatisfactory QoL outcomes after palliative radiotherapy for brain metastases, novel strategies to improve intracranial tumour control are needed. Further QoL studies are necessary to better identify patients groups who may benefit from specific modes of radiotherapy, e. g. shorter or longercourse WBRT, local (stereotactic) treatment alone or 
combinations. At the same time, a patient subgroup with very poor baseline characteristics (including clinical and QoL parameters) may be defined, in whom radiotherapy can be withheld.

\section{Conclusions}

In a prospective study, QoL of patients with brain metastases deteriorated in several domains within three months of initiation of palliative radiotherapy. However, headache remained unchanged and steroid use decreased at 3 months compared to baseline. Although 3-month survivors differed in several areas of pre-treatment QoL scores from non-survivors, only the QoL score for pain was predictive of survival when clinical variables were also considered.

\section{Abbreviations \\ EORTC: European Organisation for Research and Treatment of Cancer; EORTC-QLQ-C15-PAL: Quality of life questionnaire of EORTC, shortened version with 15 questions for palliative setting; EORTC-BN20: Quality of life questionnaire of EORTC for patients with brain tumours; GPA: Graded Prognostic Assessment; Gy: Gray; hfSRT: Hypofractionated Stereotactic Radiotherapy; KPS: Karnofsky Performance Score; MeV: Mega electron Volts; QLQ: Quality of life questionnaire; QoL: Quality of life; RPA: Recursive Partitioning Analysis; RT: Radiotherapy; SRS: Stereotactic Radiosurgery; WBRT: Whole-brain Radiotherapy.}

\section{Competing interests}

The authors declare that they have no competing interests.

\section{Acknowledgement}

Open Access Publication was sponsored by DFG. Research of the first author, DS, was supported by the MHH Equal Opportunities Office. We are very grateful to Christina Soika-Giles for proofreading this paper.

\section{Author details}

${ }^{1}$ Radiation Oncology, Medical School Hannover, Hannover, Germany. ${ }^{2}$ Radiation Oncology, Martin Luther University, Halle/Saale, Germany. ${ }^{3}$ Radiation Oncology, TU München, München, Germany. ${ }^{4}$ Radiation Oncology, St.-Josef-Hospital Gelsenkirchen-Horst, Gelsenkirchen, Germany. ${ }^{5}$ Radiation Oncology Radiation Oncology, Hospital Krems, Krems, Austria. ${ }^{6}$ Radiation Oncology, University of Münster, Münster, Germany. ${ }^{7}$ Radiation Oncology, Hospital Düren, Düren, Germany. ${ }^{8}$ Radiation Oncology, University of Frankfurt/Main, Frankfurt/Main, Germany. ${ }^{9}$ Radiation Oncology, University of UIm, UIm, Germany. ${ }^{10}$ Radiation Oncology, University of Regensburg, Regensburg, Germany. ${ }^{11}$ Radiation Oncology, Hospital Traunstein, Traunstein, Germany. ${ }^{12}$ Radiation Oncology, LMU München, München, Germany. ${ }^{13}$ Radiation Oncology, Hospital Landshut, Landshut, Germany. ${ }^{14}$ Radiation Oncology, Hospital Salzburg, Salzburg, Austria. ${ }^{15}$ Radiation Oncology, University of Würzburg, Würzburg, Germany. ${ }^{16}$ Radiation Oncology, Martin Luther University Halle-Wittenberg, Halle/Saale, Germany.

\section{Author's information}

Dirk Vordermark on behalf of the Quality of Life Working Party of the German Radiation Oncology Society (DEGRO).

\section{Authors' contributions \\ DV, SS, CS and HG participated in the design of the study. YP, DV and DS performed the statistical analyses. All authors provided study material and were involved in manuscript writing; they read and approved the final manuscript. DS, BO and DV drafted the manuscript.}

Received: 21 March 2012 Accepted: 21 June 2012

Published: 10 July 2012

\section{References}

1. Steinmann D, Schäfer C, van Oorschot B, Wypior HJ, Bruns F, Bölling T, Sehlen S, Hagg J, Bayerl A, Geinitz H, Hipp M, Vordermark D: Effects of radiotherapy for brain metastases on quality of life (QoL). Prospective pilot study of the DEGRO QoL working party. Strahlenther Onkol 2009, 185:190-197.

2. Wong J, Hird A, Kirou-Mauro A, Napolskikh J, Chow E: Quality of life in brain metastases radiation trials: a literature review. Curr Oncol 2008, 15 (5):25-45.

3. Wong J, Hird A, Zhang L, Tsao M, Sinclair E, Barnes E, Danjoux C, Chow E: Symptoms and quality of life in cancer patients with brain metastases following palliative radiotherapy. Int I Radiat Oncol Biol Phys 2009, 75 (4):1125-1131.

4. Caissie A, Nguyen J, Chen E, Zhang L, Sahgal A, Clemons M, Kerba M, Arnalot PF, Danjoux C, Tsao M, Barnes E, Holden L, Danielson B, Chow E: Quality of Life in Patients with Brain Metastases Using the EORTC QLQBN20+2 and QLQ-C15-PAL. Int J Radiat Oncol Biol Phy 2011, Dec 13. [Epub ahead of print].

5. Chow E, Davis L, Holden L, Tsao M, Danjoux C: Prospective assessment of patient-rated symptoms following whole brain radiotherapy for brain metastases. J Pain Symptom Manage 2005, 30(1):18-23.

6. Barnes EA, Chow E, Tsao MN, Bradley NM, Doyle M, Li K, Lam K, Danjoux C: Physician expectations of treatment outcomes for patients with brain metastases referred for whole brain radiotherapy. Int I Radiat Oncol Biol Phys 2010, 76(1):187-192

7. Temel JS, Greer JA, Admane S, Gallagher ER, Jackson VA, Lynch TJ, Lennes IT, Dahlin CM, Pirl WF: Longitudinal perceptions of prognosis and goals of therapy in patients with metastatic non-small-cell lung cancer: results of a randomized study of early palliative care. J Clin Oncol 2011, 29 (17):2319-2326.

8. Gaspar L, Scott C, Rotman M, Asbell S, Phillips T, Wasserman T, McKenna WG, Byhardt R: Recursive partitioning analysis (RPA) of prognostic factors in three Radiation Therapy Oncology Group (RTOG) brain metastases trials. Int J Radiat Oncol Biol Phys 1997, 37(4):745-751.

9. Gaspar LE, Scott C, Murray K, Curran W: Validation of the RTOG recursive partitioning analysis (RPA) classification for brain metastases. Int J Radiat Oncol Biol Phys 2000, 47(4):1001-1006.

10. Meyer A, Steinmann D, Malaimare L, Karstens JH, Bremer M: Prediction of prognosis regarding fractionation schedule and survival in patients with whole-brain radiotherapy for metastatic disease. Anticancer Res 2008, 28 (6B):3965-3969.

11. Rades D, Dziggel L, Haatanen T, Veninga T, Lohynska R, Dunst J, Schild SE: Scoring systems to estimate intracerebral control and survival rates of patients irradiated for brain metastases. Int I Radiat Oncol Biol Phys 2011, 80(4):1122-1127.

12. Sperduto CM, Watanabe Y, Mullan J, Hood T, Dyste G, Watts C, Bender GP, Sperduto P: A validation study of a new prognostic index for patients with brain metastases: the Graded Prognostic Assessment. I Neurosurg 2008, 109(Suppl):87-89.

13. Mahoney FI: BARTHEL DW: Functional Evaluation: the Barthel Index. Md State Med J 1965, 14:61-65.

14. Aaronson NK, Ahmedzai S, Bergman B, Bullinger M, Cull A, Duez NJ, Filiberti A, Flechtner H, Fleishman SB, de Haes JC: The European Organization for Research and Treatment of Cancer QLQ-C30: a quality-of-life instrument for use in international clinical trials in oncology. J Natl Cancer Inst 1993, 85(5):365-376.

15. Groenvold M, Petersen MA, Aaronson NK, Arraras JI, Blazeby JM, Bottomley A, Fayers PM, de Graeff A, Hammerlid E, Kaasa S, Sprangers MA, Bjorner JB: EORTC Quality of Life Group: The development of the EORTC QLQ-C15PAL: a shortened questionnaire for cancer patients in palliative care. Eur J Cancer 2006, 42(1):55-64.

16. Fayers PM: Interpreting quality of life data: population-based reference data for the EORTC QLQ-C30. Eur J Cancer 2001, 37(11):1331-1334.

17. Slotman BJ, Mauer ME, Bottomley A, Faivre-Finn C, Kramer GW, Rankin EM, Snee M, Hatton M, Postmus PE, Collette L, Senan S: Prophylactic cranial irradiation in extensive disease small-cell lung cancer: short-term health-related quality of life and patient reported symptoms: results of an international Phase III randomized controlled trial by the EORTC Radiation Oncology and Lung Cancer Groups. J Clin Oncol 2009, 27(1):78-84.

18. Osoba D, Rodrigues G, Myles J, Zee B, Pater J: Interpreting the significance of changes in health-related quality-of-life scores. J Clin Oncol 1998, 16 (1):139-144

19. Addeo R, Caraglia M, Faiola V, Capasso E, Vincenzi B, Montella L, Guarrasi R, Caserta L, Del Prete S: Concomitant treatment of brain metastasis with 
whole brain radiotherapy [WBRT] and temozolomide [TMZ] is active and improves quality of life. BMC Cancer 2007, 7:18.

20. Bezjak A, Adam J, Barton R, Panzarella T, Laperriere N, Wong CS, Mason W, Buckley C, Levin W, McLean M, Wu JS, Sia M, Kirkbride P: Symptom response after palliative radiotherapy for patients with brain metastases. Eur J Cancer 2002, 38(4):487-496.

21. Sehlen S, Lenk M, Hollenhorst H, Schymura B, Aydemir U, Herschbach $P$, Duhmke E: Quality of life (QoL) as predictive mediator variable for survival in patients with intracerebral neoplasma during radiotherapy. Onkologie 2003, 26(1):38-43.

22. Taphoorn MJ, Claassens L, Aaronson NK, Coens C, Mauer M, Osoba D, Stupp R, Mirimanoff RO, van den Bent MJ, Bottomley A: EORTC Quality of Life Group, and Brain Cancer, NCIC and Radiotherapy Groups: An international validation study of the EORTC brain cancer module (EORTC QLQ-BN20) for assessing health-related quality of life and symptoms in brain cancer patients. Eur J Cancer 2010, 46(6):1033-1040.

23. Roos DE, Wirth A, Burmeister BH, Spry NA, Drummond KJ, Beresford JA, McClure BE: Whole brain irradiation following surgery or radiosurgery for solitary brain metastases: mature results of a prematurely closed randomized Trans-Tasman Radiation Oncology Group trial (TROG 98.05). Radiother Oncol 2006, 80(3):318-322.

24. Gerrard GE, Prestwich RJ, Edwards A, Russon LJ, Richards F, Johnston CF, Kwok-Williams MC: Investigating the palliative efficacy of whole-brain radiotherapy for patients with multiple-brain metastases and poor prognostic features. Clin Oncol (R Coll Radiol) 2003, 15(7):422-428.

25. Sperduto PW, Berkey B, Gaspar LE, Mehta M, Curran W: A new prognostic index and comparison to three other indices for patients with brain metastases: an analysis of 1,960 patients in the RTOG database. Int J Radiat Oncol Biol Phys 2008, 70(2):510-514.

26. Sperduto PW, Chao ST, Sneed PK, Luo X, Suh J, Roberge D, Bhatt A, Jensen AW, Brown PD, Shih H, Kirkpatrick J, Schwer A, Gaspar LE, Fiveash JB, Chiang $\checkmark$, Knisely J, Sperduto CM, Mehta M: Diagnosis-specific prognostic factors, indexes, and treatment outcomes for patients with newly diagnosed brain metastases: a multi-institutional analysis of 4,259 patients. Int J Radiat Oncol Biol Phys 2010, 77(3):655-661.

27. Koyfman SA, Tendulkar RD, Chao ST, Vogelbaum MA, Barnett GH, Angelov L, Weil RJ, Neyman G, Reddy CA, Suh JH: Stereotactic radiosurgery for single brainstem metastases: the cleveland clinic experience. Int J Radiat Oncol Biol Phys 2010, 78(2):409-414.

28. Feyer P, Sautter-Bihl ML, Budach W, Dunst J, Haase W, Harms W, Sedlmayer F, Souchon R, Wenz F, Sauer R: Breast Cancer Expert Panel of the German Society of Radiation Oncology (DEGRO): DEGRO Practical Guidelines for palliative radiotherapy of breast cancer patients: brain metastases and leptomeningeal carcinomatosis. Strahlenther Onkol 2010, 186(2):63-69.

29. Tang V, Rathbone M, Park Dorsay J, Jiang S, Harvey D: Rehabilitation in primary and metastatic brain tumours: impact of functional outcomes on survival. J Neurol 2008, 255(6):820-827.

30. Lagerwaard FJ, Levendag PC, Nowak PJ, Ejjkenboom WM, Hanssens PE, Schmitz PI: Identification of prognostic factors in patients with brain metastases: a review of 1292 patients. Int J Radiat Oncol Biol Phys 1999, 43(4):795-803.

31. Eichler AF, Kuter I, Ryan P, Schapira L, Younger J, Henson JW: Survival in patients with brain metastases from breast cancer: the importance of HER-2 status. Cancer 2008, 112(11):2359-2367.

32. Li J, Bentzen SM, Renschler M, Mehta MP: Regression after whole-brain radiation therapy for brain metastases correlates with survival and improved neurocognitive function. J Clin Oncol 2007, 25(10):1260-1266.

33. Movsas B, Moughan J, Sarna L, Langer C, Werner-Wasik M, Nicolaou N, Komaki R, Machtay M, Wasserman T, Bruner DW: Quality of life supersedes the classic prognosticators for long-term survival in locally advanced non-small-cell lung cancer: an analysis of RTOG 9801. J Clin Oncol 2009, 27(34):5816-5822.

34. Montazeri A, Milroy R, Hole D, McEwen J, Gillis CR: Quality of life in lung cancer patients: as an important prognostic factor. Lung Cancer 2001, 31(2-3):233-240.

35. Montazeri A: Quality of life data as prognostic indicators of survival in cancer patients: an overview of the literature from 1982 to 2008. Health Qual Life Outcomes 2009, 7:102.

36. Gotay CC, Kawamoto CT, Bottomley A, Efficace F: The prognostic significance of patient-reported outcomes in cancer clinical trials. J Clin Oncol 2008, 26(8):1355-1363.
37. Brown PD, Ballman KV, Rummans TA, Maurer MJ, Sloan JA, Boeve BF, Gupta L, Tang-Wai DF, Arusell RM, Clark MM, Buckner JC: Prospective study of quality of life in adults with newly diagnosed high-grade gliomas. J Neurooncol 2006, 76(3):283-291.

38. Sundaresan P, Yeghiaian-Alvandi R, Gebski V: Prognostic index to identify patients who may not benefit from whole brain radiotherapy for multiple brain metastases from lung cancer. J Med Imaging Radiat Oncol 2010, 54(1):69-75.

doi:10.1186/1471-2407-12-283

Cite this article as: Steinmann et al:: Prospective evaluation of quality of life effects in patients undergoing palliative radiotherapy for brain metastases. BMC Cancer 2012 12:283.

\section{Submit your next manuscript to BioMed Central and take full advantage of:}

- Convenient online submission

- Thorough peer review

- No space constraints or color figure charges

- Immediate publication on acceptance

- Inclusion in PubMed, CAS, Scopus and Google Scholar

- Research which is freely available for redistribution

Submit your manuscript at www.biomedcentral.com/submit
C Biomed Central 